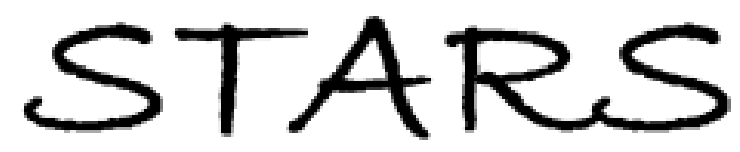

University of Central Florida

STARS

$1-1-1980$

\title{
Candidate Images Among Voters And Non-Voters In 1976
}

William S. Maddox

University of Central Florida

Find similar works at: https://stars.library.ucf.edu/facultybib1980

University of Central Florida Libraries http://library.ucf.edu

This Article is brought to you for free and open access by the Faculty Bibliography at STARS. It has been accepted for inclusion in Faculty Bibliography 1980 s by an authorized administrator of STARS. For more information, please contact STARS@ucf.edu.

\section{Recommended Citation}

Maddox, William S., "Candidate Images Among Voters And Non-Voters In 1976" (1980). Faculty

Bibliography 1980s. 22.

https://stars.library.ucf.edu/facultybib1980/22

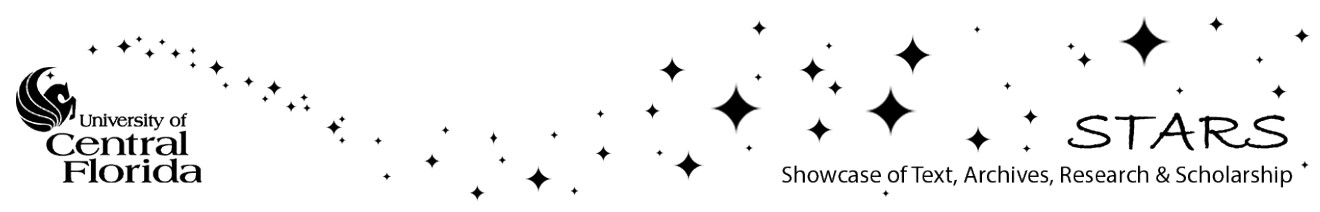




\title{
CANDIDATE IMAGES AMONG VOTERS AND NONVOTERS IN 1976
}

\author{
WILLIAM S. MADDOX \\ University of Central Florida
}

An analysis of 1976 data indicates that nonvoters' images of presidential candidates do not differ drastically from the images expressed by voters. Nonvoters respond to fewer candidates and tend to rate some "outsider" figures more positively and "establishment" figures less positively. With regard to most candidates, however, nonvoters" perceptions resemble those of fellow partisan identifiers more than those of fellow nonvoters. Tests of candidate-related explanations of turnout provide more support for the "indifference" and "other preference" hypotheses than for alienation, but the utility of these explanations varies across partisan groupings.

What is the nature of nonvoter responses to candidates in presidential elections? One view is that nonvoters prefer some other figure and are unimpressed by the two major candidates. Commentators on the 1976 election particularly focused on this possibility, attributing the low turnout to lack of enthusiasm for the two choices (Louis Harris, Inc., 1976) or noting that "while neither candidate aroused the enmity of of the electorate, neither aroused its enthusiasm" (Pomper, 1977). Another proposition is that, regardless of their first choice for president, citizens who see little difference between the major candidates are less likely to vote (Brody and Page, 1973, provide empirical support for this view). A more complex theory is that nonvoters are alienated from candidates in that they either dislike all of them equally or they see distinctions between them but rate all of them lower than voters do. Much of the traditional political science literature suggests this (see Milbrath and Goel, 1977, for a

Author's Note: I would like to thank Professor Dan Nimmo of the University of Tennessee for his encouraging words regarding an earlier version of this work. 
summary), and Brody and Page (1973) find some support for the alienation thesis, although not as much as for indifference as a cause of nonvoting.

Thus, there are several hypotheses about nonvoters' comparative ranking of candidate preferences. The other preference hypothesis predicts that nonvoters do not vote because their favorite is not in the final race; the highest rankings by nonvoters would go to noncandidates, while the two major candidates would be rated significantly lower. The indifference hypothesis suggests only that there will be little difference between nonvoters' ratings of the two major candidates (while voters would see greater differences), suggesting indifference to candidates as the major determinant of nonvoting. The alienation argument suggests two possible rating outcomes by nonvoters, although both reflect the same cause of nonvoting. First, nonvoters may perceive all candidates to be alike, in a negative way. Thus, their ratings of most candidates would cover a narrow range demonstrating equal hostility to all candidates. Alternatively, alienated nonvoters may see distinctions between candidates, possibly even rating them in the same order as do voters, but the high point of their ratings (or most favored candidate) would be lower than that of voters. Finally, hypotheses about nonvoters' candidate images are confounded by the fact that nonvoters generally respond to candidate stimuli on surveys at a lower rate than do voters.

Many studies have noted the continuing relationship of candidate images to voting behavior (see Nimmo and Savage, 1976). Most are aimed at describing the voting choice rather than turnout, however; thus their analysis is limited to the candidate images held by voters (see for example, Declerq et al., 1975; Pomper, 1975; and Miller and Miller, 1975). Others have analyzed how all citizens respond to candidates, but their analyses deal with perception of candidates by the total public. They may compare whites and nonwhites (Miller and Miller, 1975) or partisan groupings (Weisberg and Rusk, 1970; Rusk and Weisberg, 1972), but they do not compare voters and nonvoters. The Brody and Page study (1973), from which the in- 
difference and alienation hypotheses emerge, compares voters and nonvoters, but not with regard to specific candidates or relative evaluations of candidates by the two groups. We do know that nonvoters more often are less enthusiastic about candidates than voters and see fewer differences between the major candidates (Brody and Page, 1973), that many but not all candidate images for the general public depend in part on the partisanship of the citizen (Rusk and Weisberg, 1972), and that nonvoters as a group have partisan tendencies distinct from those of voters (Perry, 1973; Milbrath and Goel, 1977).

We do not know, however, whether the relationship between partisanship and candidate images exists equally for voters and nonvoters or whether the images of candidates held by nonvoters differ from those held by voters in ways which are not just a reflection of partisan differences between the two groups. In general, we lack recent evidence to answer a basic question: Are there differences in the responses to candidates by voters and nonvoters that, apart from partisan differences, support one of the three hypothesized explanations of nonvoting in presidential elections? More simply stated, do nonvoters hold images of candidates which are more like those images held by other nonvoters or more like the images of candidates held by their fellow partisans who do vote?

\section{PARTISANSHIP VERSUS TURNOUT}

A simple test of these questions is possible, using the 1976 Center for Political Studies National Election Study.' Twelve of the 1976 presidential candidates (or potential candidates) were presented to respondents to be evaluated on the "feeling thermometer" scale. Respondents could rate candidates from 0 to 100 in terms of how favorably they felt toward the person. To determine if differences in candidate affective images held by voters and nonvoters are attributable to partisan identification, to the nonvoter-voter distinction, or to both, a separate analysis of variance was performed for each of the candidates 
rated. ${ }^{2}$ The candidate rating thus was treated as the dependent variable; party identification and turnout (in the presidential race) were treated as classification variables. The analyses of variance summarized in Table 1 demonstrate whether there were significant differences in candidate ratings between voters and nonvoters, between partisans, or both.

There were no significant differences attributable to partisanship for only one candidate, George Wallace, the primary party outsider of the decade (Weisberg and Rusk, 1970; Rusk and Weisberg, 1972). There was a significant tendency, however, for nonvoters to rate Wallace more positively (although their mean rating of him was only 48.5 ) than voters did. The second major finding displayed in Table 1 is that there were three other candidates, Kennedy, Humphrey, and Reagan, for whom there were clear differences both across partisan groupings (as noted in earlier research) and between voters and nonvoters. The partisan differences were in the expected direction, with Republicans rating Reagan more positively than others did and Democrats being the group most favorable toward Kennedy and Humphrey. Significant differences existed between voters and nonvoters, however, independently of partisanship; nonvoters gave higher ratings to Kennedy and lower ratings to Humphrey and Reagan than did voters. For the other candidates, there were no significant differences between voters and nonvoters in their evaluations, but there were partisan differences, all in the expected direction. Carter was rated most favorably by Democrats, independents, and Republicans, in that order; for Ford, the reverse order was the case. ${ }^{3}$ For the also-rans, the expected partisan orientations were present. The only variations worth noting are that Rockefeller is now seen distinctly as a partisan, unlike his previous position (Weisberg and Rusk, 1970), and that McCarthy, despite his independent candidacy in 1976, continued his move toward being perceived as a Democratic partisan (Rusk and Weisberg, 1972).

Are the images of candidates held by nonvoters significantly different from those of voters when partisanship is controlled? Except for four well-known figures, the answer is no. In terms 
TABLE 1

Analyses of Variance

\begin{tabular}{|c|c|c|}
\hline \multirow[t]{2}{*}{ Candidate } & \multicolumn{2}{|c|}{ F Ratio } \\
\hline & $\begin{array}{c}\text { Source: } \\
\text { Party Identification } \\
\end{array}$ & $\begin{array}{l}\text { Source: } \\
\text { Turnout }\end{array}$ \\
\hline Wallace & .2 & $14.3^{\star \star}$ \\
\hline Carter & $213.0^{\star \star}$ & .1 \\
\hline Ford & $178.1^{\star \star}$ & .4 \\
\hline Humphrey & $107.8^{\star \star}$ & $4.2^{\star}$ \\
\hline Reagan & $82 . \varepsilon^{\star \star}$ & $3.8^{\star}$ \\
\hline Kennedy & $160.3^{* \star}$ & $1 / .3^{\star \star *}$ \\
\hline Jackson & $19.4^{\star \star \star}$ & 1.2 \\
\hline Rockefeller & $14.2^{\star \star}$ & 2.3 \\
\hline Uda 11 & $40.1^{\star \star}$ & .5 \\
\hline Brown & $25.6^{\star \star}$ & .6 \\
\hline HcGovern & $88.9^{\star \star}$ & 2.1 \\
\hline McCarthy & $7.5^{\star \star}$ & 1.9 \\
\hline
\end{tabular}

${ }^{* p}<.05 ; * *_{p}<.01$

of images of the major presidential candidates in 1976 (and the also-rans), nonvoters are more like their fellow partisans than they are like their fellow nonvoters. Wallace and Kennedy are seen more positively by nonvoters, but that fact may provide evidence of alienation, to the extent that people perceive them as outsiders and symbols of alienation. The lower nonvoter ratings of Humphrey and Reagan represent an alienation from two partisan war-horses of contemporary politics. Thus, if there was alienation among nonvoters in 1976, it was expressed in response to familiar figures but not to the major presidential candidates. 


\section{CANDIDATE IMAGES AMONG PARTISAN GROUPINGS}

Since there were significant differences among partisan groups for all candidates except Wallace, our investigation of the sources of nonvoting could profit by a more detailed examination of the candidate images held by voters and nonvoters within each partisan group. Tests of the three hypotheses described earlier will make sense only if performed for each group separately. For Democrats, Republicans, and independents, we will analyze for both voters and nonvoters the relative ranking of all candidates as Weisberg and Rusk (1970) did for their total sample. This procedure provides a test of the other preference hypothesis. The general range of scores for all candidates will provide further evidence as to the existence of alienation, if nonvoters in each category demonstrate either a narrower or a more negative range of mean scores for candidates than do their fellow partisans who voted. Third, we can compare within each group the ratings of Ford and Carter. Controlling for partisanship, indifference as a cause of nonvoting should be reflected by voters perceiving greater distinctions between the two than nonvoters do. Initially, however, we note the differences in response rate between voters and nonvoters in each category of partisanship. Table 2 displays for each group the mean rating of all those responding to each candidate, the percentage of nonresponses, and the range of scores for each group.

Before the more detailed analyses, we can summarize the nonresponse tendencies across all groups. As expected, there is a much higher "no response" rate among nonvoters than among voters. In fact, for twelve candidates rated by three different partisan groupings, there is not a single case where nonvoters responded more often to a candidate than did their fellow partisans who voted. Furthermore, there is a much higher "no response" rate for some candidates than others, but those same candidates (Brown, Udall, Jackson, and McCarthy) lack image definition among both voters and nonvoters; the rate is simply exaggerated for all candidates among nonvoters. Finally, 


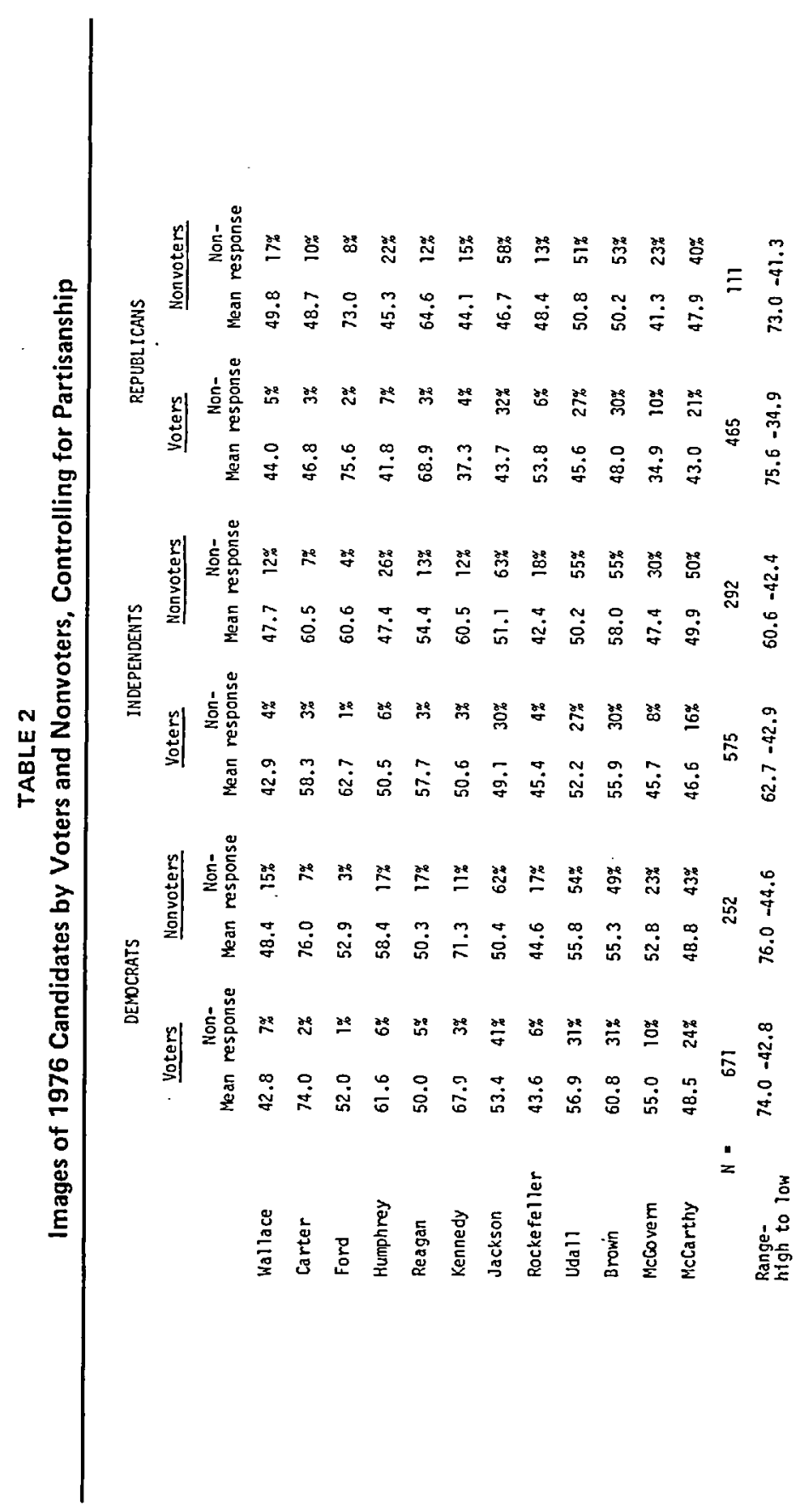


the only partisan tendencies toward nonresponse are that, as we might expect, partisans are slightly more likely to abstain from evaluating candidates of the other party and independents demonstrate a slightly higher nonresponse rate in both the voting and nonvoting groups. Within this context, we can look at the differences between voter-nonvoter candidate images within each partisan group.

Among Democrats, the mean scores for their favorite, Carter, are almost identical for voters and nonvoters. In fact, the first three preferred candidates were the same for both groups: Carter, Kennedy, and Humphrey. The fourth- and fifth-place ratings included the same two men, Brown and Udall, although their rankings were reversed for voters and nonvoters. Nonvoting Democrats gave Wallace a higher mean score than did voters, but even they failed to rate him favorably. The only evidence for the other preference hypothesis is the significantly higher score for Kennedy among nonvoters, indicating that there may be many in this group who did prefer Kennedy over Carter, a fact which the averaging of scores could obscure.

Among independents, three of the four highest ratings are the same among voters and nonvoters. Ford and Carter are first and second by these mean scores; Brown is fourth in both groups. Among those independents who voted, Reagan earned a third place among all candidates, while Kennedy is rated barely on the positive side of the feeling thermometer by these voters. Among nonvoting independents, although Ford and Carter are still rated highest, Kennedy scores significantly higher and is virtually tied with the two nominees for the highest mean score. Among these nonvoters, Reagan is seen in only slightly positive terms, significantly lower than among voters. For independents, then, there is evidence that sympathy for another candidate, Kennedy, existed among nonvoters, although that does not reflect hostility toward Ford and Carter.

Finally, Republican partisans rated Ford virtually the same (and highest), regardless of their turnout. Although Reagan received the second highest mean score among both groups, he was scored significantly higher by the voting Republicans, 
indicating little evidence that the most disgruntled Reaganites sat out the election. Voting Republicans rate Rockefeller third and the Democrat Brown fourth, although no candidates other than Ford or Reagan are seen very positively. Nonvoting Republicans rate two Democrats, Udall and Brown, third and fourth, but the small sample size and high nonresponse rate for that group cautions against too much interpretation. Although Kennedy's rating is higher among nonvoters in all three partisan groups, it is among independents and Democrats that there is evidence for the "other preference" explanation of nonvoting. No such evidence appears for Republican nonvoters.

The range of mean scores was about 32 points for both voting and nonvoting Democrats. The fact that the range for nonvoters was slightly more positive than that of voters offers little evidence of general candidate alienation. Only the higher nonresponse rate among nonvoters supports such a thesis and, even there, there was little nonresponse among nonvoters to the two major party candidates. Of course, the nonresponses may reflect mere apathy and disinterest. Both voting and nonvoting independents demonstrated similar and fairly narrow ranges of mean scores. Furthermore, their highest candidate ratings are much lower than those of partisan groupings. Even among those candidates who conceivably could project a nonpartisan image to these citizens (Wallace, McCarthy, and Brown), only the new face, Jerry Brown, earns a distinctly positive rating, and he suffers from substantial nonresponse. Voting Republicans demonstrate the widest range of scores of any group, 40 points between the mean score for Ford and the lowest rating, that for McGovern. Nonvoting Republicans, on the other hand, display a 32-point range similar to that of both types of Democrats. This difference in ranges, however, is probably an indication of strong partisan evaluations of candidates among voting Republicans, and gives us no evidence that nonvoting Republicans abstain because of general alienation. Thus, alienation from candidates distinguishes not so much between voters and nonvoters but between independents and partisans. 
Finally, mean scores among voting Democrats demonstrate a 22-point difference between Carter and Ford; for nonvoting Democrats, the difference was 23 points. There is some evidence that indifference is associated with nonvoting among independents, however. Although the Ford-Carter difference on mean scores was not large among voting independents, it was nonexistent among nonvoting independents. Although the three-way tie for first place and the relatively narrow range of mean scores suggest that Brody and Page's (1973) "information capacity" model ${ }^{4}$ may explain both candidate images and turnout behavior among independents, we must note that both sets of independents did see differences between candidates: After the top four candidates in each group, evaluations drop dramatically. On the average, voting Republicans perceived a slightly greater difference between the two major party nominees than nonvoters, but even nonvoting Republicans demonstrated drastically different mean scores for Ford and Carter. Given the small sample of nonvoting Republicans and the ambiguous nature of these results, conclusions about nonvoting among Republicans are difficult to draw. Only a slightly greater enthusiasm for both Ford and Reagan among voting Republicans suggests that relative lack of enthusiasm for candidates in general explains nonvoting among this partisan group.

\section{CONCLUSIONS}

Our major finding is that we must analyze sources of nonvoting separately for partisan groupings. As for the three hypotheses stated earlier, there is little evidence among any group that nonvoters demonstrate severe alienation from candidates. Indifference, in the sense that a person simply may not respond to candidates, clearly distinguishes voters and nonvoters in terms of candidates in general, but not as much in terms of the major party candidates: The highest nonresponse rate to one of the major candidates was $10 \%$ toward Carter among nonvoting Republicans. If indifference means that the 
two candidates are perceived as virtually the same, it seems to be a factor only among independents. Finally, there is some indication that the other preference hypothesis explains nonvoting for some independents and, to a lesser extent, Democrats.

Nonvoters tended to see the two major party candidates about the same as did their fellow partisans; although some of them may have preferred someone else, they certainly were no more "turned off" by their party's nominee than were the voters. Nonvoters also saw the "also-rans" of 1976 in about the same way as did their fellow partisans who voted; nonvoters' response rate to those candidates, however, was distinctly lower. Finally, nonvoters saw four candidates differently from voters, even with partisanship controlled. Nonvoters may in fact have been attracted by the Kennedy charisma: Edward Kennedy was rated significantly higher by nonvoters than by voters in all three partisan groupings. Wallace was also rated significantly higher by nonvoters of all party affiliations; in none of them, however, did his mean rating reach the midpoint of the feeling thermometer. Two partisan symbols received significantly different ratings from voters and nonvoters when partisanship was controlled. Humphrey is scored lower by nonvoting Democrats and independents but higher by nonvoting Republicans. Nonvoting Republicans and independents ranked Reagan lower than their voting counterparts, while there was no difference in his ratings from voting and nonvoting Democrats. Nonvoters, then, were less sympathetic to the "old faces" of American politics than were voters, but most of the "newer faces" of the 1970s had yet to make an impression upon them in 1976. The popular concept that many nonvoters may be waiting for an outsider to lead them into political participation, however, does receive some confirmation in these findings.

\section{NOTES}

1. The data utilized in this report were made available by the Inter-University Consortium for Political and Social Research and were originally collected by the University 
of Michigan Center For Political Studies. Neither the Consortium nor the CPS bear any responsibility for the analysis or interpretations presented here.

2. Four other men were listed under the feeling thermometer section, but their scores are not considered here: Richard Nixon, Henry Kissinger, and the two vice-presidential candidates, Walter Mondale and Robert Dole. Although Mondale was an unofficial candidate for president in 1975 , we assume that the response to him in the 1976 survey primarily represent images of him in the role of vice-presidential candidate.

3. Although not listed in Table I, the vice-presidential candidates Mondale and Dole experienced the same ranking tendencies across partisans and turnout groups as did their running mates.

4. The incapacity model, for which Brody and Page found little evidence in 1968, states that lack of political information or interest is the cause of three otherwise unrelated behaviors: inability to respond to the candidates, indifference toward the major nominees, and nonvoting.

\section{REFERENCES}

BRODY, R. A. and B. I. PAGE (1973) "Indifference, alienation, and rational decisions." Public Choice 15 (Summer): 1-17.

DECLERQ, E. et al. (1975) "Voting in American presidential elections: 1956-1972." Amer. Politics Q. 3 (July): 222-246.

Louis Harris, Inc. (1976) The Harris Survey, November 11.

Milbrath, L. W. and M. L. GOEL (1977) Political Participation. Skokie, IL: Rand MeNally.

MILLER, A. H. and W. E. MILLER (1975) “Issues, candidates, and partisan divisions in the 1972 American presidential election." British J. of Pol. Sci. 5 (October): 393434.

NIMMO, D. and R. L. SAVAGE (1976) Candidates and Their Images. Santa Monica, CA: Goodyear.

PERRY, P. (1973) "A comparison of the voting preferences of likely voters and likely nonvoters." Public Opinion Q. 37 (Spring): 99-109.

POMPER, G. (1977) The Election of 1976. New York: David McKay.

_-_ (1975) Voters' Choice. New York: Harper \& Row.

RUSK, J. G. and H. F. WEISBERG (1972) "Perceptions of presidential candidates: implications for electoral change." Midwest J. of Pol. Sci. 16 (August): 388-410.

WEISBERG, H. F. and J. G. RUSK (1970) "Dimensions of candidate evaluations." Amer. Pol. Sci. Rev. 64 (December): 1167-1185.

William S. Maddox is Assistant Professor of Political Science at the University. of Central Florida. Orlando, Florida. His current research areas include electoral behavior. paricipation. and political psychology: His work has been published in the American Journal of Political Science and Social Science Quarterly. 